\title{
Cooper-Carbon Nanostructured Composite Coatings with Controlled Structure
}

\author{
P. I. Vysikaylo1, V. S. Mitin², A. A. Markin², A. Yu. Yakovlev1, V. V. Belyaev ${ }^{3,4}$ \\ ${ }^{1}$ Moscow Radiotechnical Institute RAS, Moscow, Russia \\ ${ }^{2}$ A.A. Bochvar All-Russia Research Institute of Inorganic Materials, Moscow, Russia \\ ${ }^{3}$ Moscow Region State University, Moscow, Russia \\ ${ }^{4}$ Peoples' Friendship University of Russia, Moscow, Russia \\ Email: filvys@ yandex.ru
}

Received 19 February 2016; accepted 28 March 2016; published 31 March 2016

Copyright (C) 2016 by authors and Scientific Research Publishing Inc.

This work is licensed under the Creative Commons Attribution International License (CC BY). http://creativecommons.org/licenses/by/4.0/

\section{(c) (i) Open Access}

\begin{abstract}
Samples of the $\mathrm{Cu}-\mathrm{C}$ composite coatings were produced by high-speed ion-plasma magnetron sputtering (HiPMS) with mosaic target (MT). Nanostructure, roughness, mechanical properties as well as electric properties of coatings depend on carbon-cooper ratio. So $10 \%-15 \%$ cooper concentration (atomic) results in to dry friction coefficient decrease up to 0.1 and wear resistance increase up to $10^{-17} \mathrm{~m}^{3} / \mathrm{N} \cdot \mathrm{m}$. The HiPMS method allowed us to effectively sputter very different materials like carbon and cooper at the same velocity with required proportion. At the same time, one could obtain a uniform mixture of ingredients on the atomic level. The coating corresponds to a mixture of nano-sized phases of carbon and cooper. Crystalline dispersion of samples depends on carbon concentration. The obtained products are characterized by XRD, UV (257 $\mathrm{nm}$ ) and visible $(514 \mathrm{~nm})$ Raman spectroscopy. The morphologies are studied with TEM and AFM. Mechanical properties were investigated with friction coefficient and micro hardness tests. There was no chemical interaction during $\mathrm{Cu}-\mathrm{C}$ precipitation on hot substrate (625 - $725 \mathrm{~K}$ ). The mechanical properties can be explained by free electrons capture with carbon nanostructures and space charge formation.
\end{abstract}

\section{Keywords}

Cu-C Nanocomposite, Coatings, Hardness, Friction Coefficient, X-Ray Diffraction, Raman Spectroscopy

\section{Introduction}

To-date nanotechnology is particularly in demand in mechanical engineering. Reduced coefficients of friction

How to cite this paper: Vysikaylo, P.I., Mitin, V.S., Markin, A.A., Yakovlev, A.Yu. and Belyaev, V.V. (2016) Cooper-Carbon Nanostructured Composite Coatings with Controlled Structure. Open Journal of Applied Sciences, 6, 195-207.

http://dx.doi.org/10.4236/ojapps.2016.63021 
and wear in machine parts and mechanisms are relevant for engineering and other fields of science and technology. For these purposes various types of solid lubricant materials are developed with chemical resistance, reduced residual stress adhesion fitted to various substrates, low shear strength and a low coefficient of friction. These properties result in high wear resistance. A nanocomposite copper-graphite is of interest among these materials. It is used as a coating on the friction surfaces. [1] There are various methods of making such coatings, which include electrochemical deposition [2], vacuum arc (ARC-PVD) [3] and plasma enhanced chemical vapor deposition (PECVD) [4]. However, all these methods are based on sequential deposition of copper carbon, which hinders the formation of the composite material with 3D-structure. In this paper, a method of high-speed ion-plasma magnetron sputtering (HiPMS) was used to obtain a composite coating of copper-carbon. It allows simultaneous spraying of copper and carbon atoms from one target. This scheme allows simultaneous efficient spraying to obtain composite coatings with controlled 3D nanostructure and high cohesion. A process of management of the structure, its composition and properties of is performed by the magnetron discharge power as well as ratio of the copper and carbon components in the original target. One of the significant advantages of the HiPMS method is high sputtering rate and hence the deposition speed of the coating with high adhesion. This makes it possible to apply coatings in thicknesses ranging from 0.1 to 500 micron. Such coatings properties are investigated in the article presented.

\section{Sample Manufacturing and Analysis Methods}

To layer a composite copper-carbon film, a high-performance industrial unit VU-MAF 600/4(MES-60) was used [5] [6]. In the vacuum unit working chamber a sputtering module was mounted, consisting of a high-speed ion-plasmous magnetron sputter of $10 \mathrm{~kW}$ with a target of $\varnothing 98 \mathrm{~mm}$; anion source with cold cathode with output up to $1.5 \mathrm{~kW}$, and the ion beam current of $800 \mathrm{~mA}$; a thermal heater with capacity up to15 $\mathrm{kW}$ and a maximum heating temperature up to $750^{\circ} \mathrm{C} \pm 20^{\circ} \mathrm{C}$; substrate holder with area up to $2.0 \mathrm{dm}^{2}$ [5] [6]. To layer the composite copper-carbon coating, the mosaic targets of special design were used as a basic material. To sputter a composite coating a series of targets was produced. The targets were sputtered in a high-speed mode at a power density level $>40 \mathrm{~W} / \mathrm{cm}^{2}$ (current density $>100 \mathrm{~mA} / \mathrm{cm}^{2}$ ). The copper-carbon composite coatings were deposited on various types of substrates and samples: 10/18 stainless steel-plates, plain washers with polished $\left(R_{\mathrm{a}} \sim 18-20 \mathrm{~nm}\right)$ and faceted $\left(R_{\mathrm{a}} \sim 500\right.$ - $\left.800 \mathrm{~nm}\right)$ surface; M1 copper-plates; ceramics of $\mathrm{Al}_{2} \mathrm{O}_{3}$-plates; quartz borosilicate glassplates; single-crystal silicon-plates. The coating tests were done: thicknesses, adhesion, friction coefficient, wear resistance and electrical resistance. The coating layer thickness was determined by the "ball-crater" method [7]. The range of layer thicknesses on the samples for various kinds of research was chosenfrom1.5 to 45 microns.

The phase composition of the coatings was investigated by XRD. The XRD measurements were performed in the Rigaku D/max-RC equipped with a $12 \mathrm{~kW}$ X-ray source with a rotary anode using monochromatic Cu-K $\alpha$ radiation and the graphite crystal-analyzer. Specification of lattice parameters, microstructure, and the spherical harmonics parameters was carried out in a MAUD software package. Accounting for instrumental broadening was performed by external standard method using a reference materialLaB 6 (NIST SRM 660a).

\section{A Research Method for the Carbon Structural State in the Composite Using the Raman Spectroscopy}

The Raman spectra were excited with the line at $514.5 \mathrm{~nm}$ and $257 \mathrm{~nm}$. The spectrograph TRIAX 552 with special corrective optics, the Notch filters and CCD camera were used for the investigation of the Raman scattering light. The spectral resolution was about $1-3 \mathrm{~cm}^{-1}$. We have used the setup of micro-Raman spectroscopy with a microscope which provided a focus diameter in the micrometer range and a large scattering collection angle.

The coating elemental composition, its surface and fracture structure were studied by field emission scanning electron microscope (SEM) LEO 1430 with a SAPHIRE add-on device for energy-dispersive spectroscopy (EDS) by Cambridge Instruments Ltd, England.

The surface local structure (topography) and its roughness class were studied using an atomic force microscope CTM/ACMCMM 2000TAMOK. In this case, a platinum probe was used with the tip size less than $50 \mathrm{~nm}$ and a standard silicon cantilever with a radius of curvature less than $10 \mathrm{~nm}$.

Investigation of the copper-carbon composite fine structure was carried out using a transmission electron microscope (TEM) of JEM-2000FX11 (JEOL) type, at an accelerating voltage of $160 \mathrm{kV}$ in the transmission mode (TEM). 
The mechanical properties of the obtained coatings were studied by the methods and devices listed below.

- The coating adhesion to the substrate (qualitative assessment) was carried out by the deep indentation technique (a diamond pyramid indenter) on a Vickers hardness tester of HVS-50 type at a 5 - $8 \mathrm{~kg}$ (50 - $80 \mathrm{~N}$ ) load on the indenter, and by a sclerometry method (scribing or scratching) with a Scratch Testing ST-300 tool by Teer Co Ltd., UK, at loads in the range $0.1-20 \mathrm{~kg}(1-200 \mathrm{~N})$. The coating microhardness was studied by metallographic method. For measurements, aHVS-1000 microhardness tester was used, with a measuring range $5-2500 \mathrm{H}_{\mathrm{V}}$, and a $0.05-0.1 \mathrm{~N}$ test force on the indenter. The samples for microhardness measurements were similar to the samples for adhesion measurements.

- The wear resistance and tribological characteristics of composite coating were determined using a specialized device-a PIN ON DISC TESTER type tribo-tester of TEER-POD-2 brand, by Teer Co Ltd., England, by a rolling-off method under dry friction of the rotating surface (a plane, a disc) by a rigidly fixed finger with a spherical contact surface, or a ball made of hard alloy, high-speed or ball-bearing steel.

- The electrical resistance of the films was measured by a four-point method on the Jandel device, RM3-AR Test Unit model, equipped with a Multi Height Microposition Probe device (positioning by X-Y axis).

\section{Results and Discussion}

Table 1 shows the experimental results on the choice of equispeed sputtering mode for a copper-graphite composite, mode 3, 4, 5 .

According to Table 1 (points 3 - 4) these compositions can be reproduce data discharge power density $>40$ $\mathrm{W} / \mathrm{cm}^{2}$. Thus, at the high-speed ion-plasmous magnetron sputtering of different materials from one target, the sputtering rate is set by the component with a maximum sputtering rate. In this case it's copper. If sputtering a

Table 1. Cu-C mosaic targets puttering modes and coating composition.

\begin{tabular}{|c|c|c|c|c|c|c|c|c|c|}
\hline \multirow{4}{*}{ № } & \multicolumn{3}{|c|}{ Target sputtering mode } & \multicolumn{2}{|c|}{ Coating deposition mode } & \multicolumn{4}{|c|}{ Coating composition and properties } \\
\hline & \multirow{2}{*}{$\begin{array}{c}\begin{array}{c}\text { Discharge } \\
\text { current }\end{array} \\
\text { A }\end{array}$} & \multirow{2}{*}{$\begin{array}{c}\begin{array}{c}\text { Current } \\
\text { density }\end{array} \\
\mathrm{mA} / \mathrm{cm}^{2}\end{array}$} & \multirow{2}{*}{$\begin{array}{l}\begin{array}{c}\text { Power } \\
\text { density }\end{array} \\
\mathrm{W} / \mathrm{cm}^{2}\end{array}$} & \multirow{2}{*}{$\begin{array}{c}\begin{array}{c}\text { Deposition } \\
\text { speed }\end{array} \\
\mu \mathrm{m} / \mathrm{min}\end{array}$} & \multirow{2}{*}{$\begin{array}{c}\begin{array}{c}\text { Substrate } \\
\text { temperature }\end{array} \\
{ }^{\circ} \mathrm{C}\end{array}$} & \multicolumn{2}{|c|}{$\begin{array}{l}\text { Element concentration, } \\
\text { at. } \%\end{array}$} & \multirow{2}{*}{$\begin{array}{c}\begin{array}{c}\text { Layer } \\
\text { thickness }\end{array} \\
\mu \mathrm{m}\end{array}$} & \multirow{2}{*}{$\begin{array}{c}\text { Roughness } \\
\mathrm{R}_{\mathrm{a}} \\
\mathrm{nm}\end{array}$} \\
\hline & & & & & & $\mathrm{Cu}$ & $\mathrm{C}$ & & \\
\hline & \multicolumn{9}{|c|}{ Pure copper target } \\
\hline 1 & 4 & 182 & 91 & 1.5 & 350 & 100 & - & 45 & $19 / 73$ \\
\hline \multicolumn{10}{|c|}{ Pure МПГ-7 graphite target } \\
\hline 2 & 2 & 91 & 46 & 0.05 & 350 & - & 100 & 1.5 & $19 / 25$ \\
\hline \multicolumn{10}{|c|}{$\mathrm{Cu}-82 \%, \mathrm{C}-18 \%$ target } \\
\hline 3 & 4 & 182 & 91 & 1.2 & 350 & 82 & 18 & 36 & 19/191 \\
\hline 4 & 2 & 91 & 46 & 0.6 & 350 & 83 & 17 & 27 & $19 / 127$ \\
\hline 5 & 1 & 22 & 16 & 0.2 & 350 & 86 & 14 & 12 & $19 / 26$ \\
\hline \multicolumn{10}{|c|}{$\mathrm{Cu}-65 \%, \mathrm{C}-35 \%$ target } \\
\hline 6 & 4 & 182 & 91 & 0.4 & 350 & 65 & 35 & 16 & $19 / 60$ \\
\hline \multicolumn{10}{|c|}{$\mathrm{Cu}-28 \%, \mathrm{C}-72 \%$ target } \\
\hline 7 & 2 & 91 & 46 & 0.1 & 350 & 28 & 72 & 4.0 & $19 / 45$ \\
\hline \multicolumn{10}{|c|}{$\mathrm{Cu}-14 \%, \mathrm{C}-\mathbf{8 6 \%} \%$ target } \\
\hline 8 & 2 & 91 & 46 & 0.08 & 350 & 14 & 86 & 4.8 & $19 / 29$ \\
\hline \multicolumn{10}{|c|}{$\mathrm{Cu}-7 \%, \mathrm{C}-93 \%$ target } \\
\hline 9 & 2 & 91 & 46 & 0.06 & 350 & 7 & 93 & 3.6 & $19 / 22$ \\
\hline
\end{tabular}

${ }^{*} R_{\mathrm{a}}$ roughness value for the coating surface is given relative to the substrate $R_{\mathrm{a}}\left(R_{\mathrm{a}}=19-20 \mathrm{~nm}\right)$. 
mosaic target using the traditional magnetrons puttering at a discharge power density up to $30 \mathrm{~W} / \mathrm{cm}^{2}$, the specified structure is not reproduced (Table 1, p. 5). In this case, both copper and graphite will be sputtered at a rate proportional to its sputtering ratio (2.2 and 0.2 respectively). In addition, sputtering in a usual mode greatly reduces the overall rate of sputtering the components and, consequently, the conditions of condensate contamination by residual gas and hydrocarbons increase. At low velocities, $<0.1 \mu \mathrm{m} / \mathrm{min}$, it is difficult to achieve high mechanical properties.

\subsection{X-Ray Research Results}

Analysis of X-ray results for the composite coatings are shown in Table 1. Analysis revealed no diffraction peaks of carbon modifications in the composites, including even the composite with a carbon content of up to93 at\%. The independent lines of any phase, showing either the copper and carbon interaction to form a carbide, or the formation of an independent carbon compound (graphite crystalline phase or a diamond-like carbon), are absent. The covering chemical composition analysis fixed (corresponding to the deposition mode and the target choice), the carbon content from 14 to 93 at\%. A comparison of composite and pure copper spectra showed that the introduction of carbon up to 72 at\% leads initially to a slight decrease in the copper lattice spacing and to a significant increase at the carbon concentration of 86 at\% and 93 at\%. In this case, the diffraction patterns of these compounds show a significant broadening of diffraction peaks as well (Table 2).

Analysis of the main diffraction peaks profiles corresponding to the crystal lattice of the copper samples with a carbon content up to 35 at\% ( 6.2 wt\%) showed that a fairly good description can be obtained in the two components approximation: a crystalline component with 100 - $150 \mathrm{~nm}$ grain sizes and an ultrafine (amorphous) component with 30 - $40 \mathrm{~nm}$ grain size.

In coatings with a carbon content $>35$ at\%, the copper phase crystallite size decreases to $50 \mathrm{~nm}$, and in ultrafine (amorphous) phase to about $20 \mathrm{~nm}$. According to Table 2, at carbon concentrations $>35$ at\%, the composite lattice parameters are much larger than the lattice parameters of pure copper. This could indicate the formation of pseudo-hard carbon solution in the metal. However, it is known that copper in the solid and liquid state is in equilibrium with graphite (carbon). So, it is incorrect to suppose the direct carbon dissolution in copper, and, apparently, here we see the capture of copper free electrons by the carbon structures. This process occurs at the final stage of coating formation on the substrate.

Table 2. X-ray structural parameters of the composites.

\begin{tabular}{|c|c|c|c|c|c|c|}
\hline \multirow{2}{*}{$\begin{array}{l}\text { Sample } \\
\text { No. }\end{array}$} & \multirow{2}{*}{$\begin{array}{l}\text { Coating } \\
\text { composition }\end{array}$} & \multirow{2}{*}{$\begin{array}{l}\text { Substrate } \\
\text { material }\end{array}$} & \multicolumn{4}{|c|}{$\mathrm{Cu}-\mathrm{C}$ coating } \\
\hline & & & $\begin{array}{l}\text { Copper lattice } \\
\text { spacing, nm }\end{array}$ & $\begin{array}{l}\text { Crystalline blocks size } \\
\text { by components, nm }\end{array}$ & $\begin{array}{l}\text { Crystalline blocks } \\
\text { size, mean value, } \mathrm{nm}\end{array}$ & $\begin{array}{c}\text { RMS } \\
\text { microdeformation, \% }\end{array}$ \\
\hline \multirow{2}{*}{9} & \multirow{2}{*}{ Pure copper } & Copper & 0.36150 & - & - & - \\
\hline & & Ch. steel ${ }^{*}$ & 0.36143 & $>150 / 37$ & 80 & 0.046 \\
\hline \multirow{2}{*}{5} & \multirow{2}{*}{14} & Ch. steel & 0.36142 & $100 / 40$ & 45 & 0.060 \\
\hline & & Silicon $^{* *}$ & 0.36150 & - & - & - \\
\hline \multirow{2}{*}{4} & \multirow{2}{*}{17} & Ch. steel & 0.36140 & $100 / 30$ & 37 & 0.120 \\
\hline & & Silicon & 0.36150 & - & - & - \\
\hline \multirow{2}{*}{3} & \multirow{2}{*}{18} & Ch. steel & 0.36156 & $56 / 25$ & 40 & 0.135 \\
\hline & & Silicon & 0.36150 & - & - & - \\
\hline 27 & 35 & Ch. steel & 0.36156 & $44 / 15$ & 22 & 0.054 \\
\hline 13 & 72 & Ch. steel & 0.36158 & $28 / 15$ & 23 & 0.230 \\
\hline 16 & 86 & Ch. steel & 0.36178 & $20 / 9$ & 19 & 0.250 \\
\hline 18 & 93 & Ch. steel & 0.36420 & 20/9 & 10 & 0.210 \\
\hline
\end{tabular}

${ }^{*}$ chrome steel lattice constant $\alpha=0.2872 \mathrm{~nm} ;{ }^{* *}$ single-crystal silicon lattice constant $\alpha=0.5415 \mathrm{~nm}$. 
For a more detailed study of the composite carbon coatings behavior, the annealing was made for coatings with a 18 at\% carbon content deposited on the silicon and chrome steel substrates. Annealing was performed in a vacuum not below $10^{-3} \mathrm{~Pa}$ for 1 hour at $650^{\circ} \mathrm{C}$. This temperature is by $100^{\circ} \mathrm{C}$ above the recrystallization temperature of copper and should ensure the mobility of the copper atoms and recrystallization with crystal growth. However, after annealing, no significant changes in the composite structures are observed. This indicates the strong bonds (possibly, the Coulomb ones) in the composite, preventing the copper atoms diffusion.

\subsection{Microscopy Structural Research Results}

The characteristic effect of carbon on the copper crystallites formation can be clearly seen from the change in the coating morphology and roughness in the atomic force microscope study of the coatings. These results indicate that initially, at low carbon concentrations, the composite coating surface roughness increases from the $R_{\mathrm{a}}$ value equal to73nmforpurecopperup to $R_{\mathrm{a}}=191 \mathrm{~nm}$, reaching a maximum at the content $18 \mathrm{at} \% \mathrm{C}$ in the coating (Table 2). Then, with increasing carbon concentrations, the surface roughness reduces to the level of $R_{\mathrm{a}}=22 \mathrm{~nm}$ at 93 at\% C, almost the same as for the pure graphite coating (Table 1, p. 2).

Here, in terms of copper crystallites formation, the coatings surface morphology nature shows that copper in its pure form has a smoother topography, Figure 1(a), and a characteristic structure of the columnar crystals directed growth. At copper and carbon codeposition, the carbon clusters are moved to the copper grain boundaries, hindering their growth. This results in blocking the 2D-growth mechanism and the crystallite growth goes up. This, apparently, explains the increase in surface roughness and the plate-like faceting of the crystallites on the composite coating surface (Figure 1(b)). With increasing carbon concentration, the "inciting" front copper crystallization upon the 3D-mechanism decays (Figure 1(c)). When the carbon concentration in the composite is 72 at\%, the crystallites topography and faceting become more smooth with a tendency to the crystallite peaks ovalizing. And when the carbon content is up to $93 \mathrm{at} \%$, the relief is smooth with small crystallites with an oval surface (Figure 1(d)). These results, on one hand, seem to confirm that the carbon is on the surface, but on the other hand, despite the chemical inertness of copper and carbon, the coating layer forms on the substrate not in the shape of separated ultrafine particles of these elements, as a compact, cohesively bonded composite material consisting of copper crystallites and carbon structures evenly distributed in the volume.

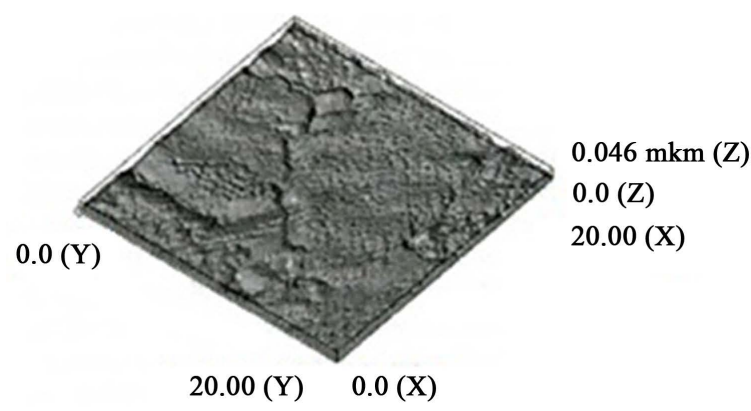

(a)

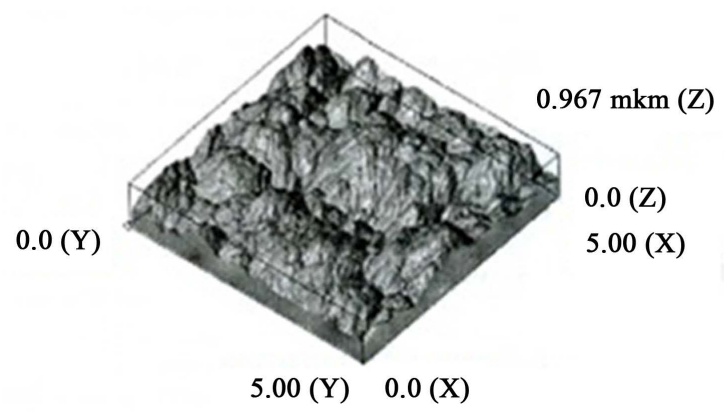

(c)

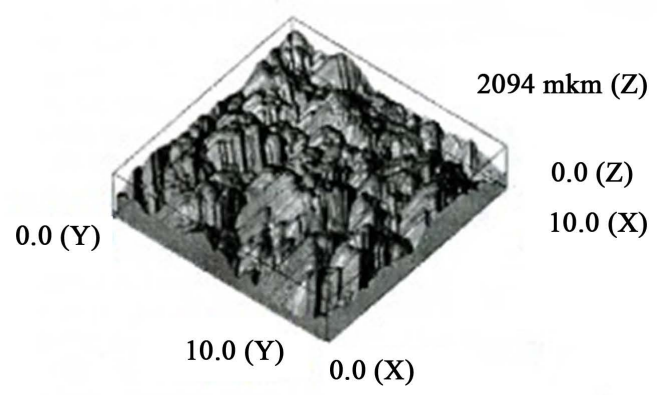

(b)

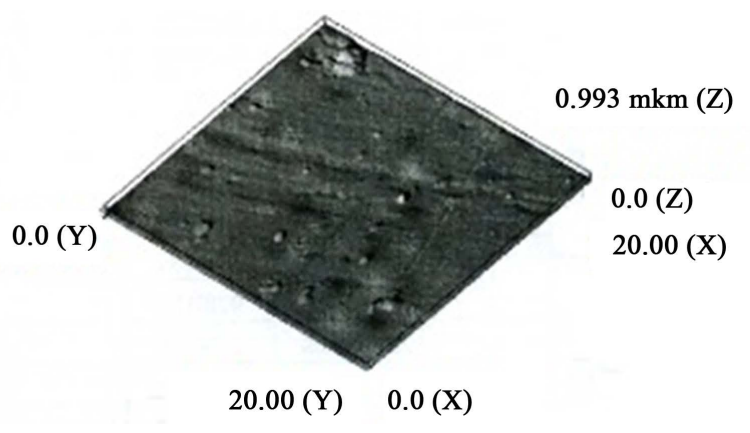

(d)

Figure 1. Atomic-force image of copper-carbon coatings, depending on the carbon concentration in the coating: (a) pure copper; (b) 18 at\% C; (c) 72 at\% C; (d) 93 at\% C. 


\subsection{Raman Research Results}

Raman spectra of the composite film, Figure 2, are characterized by broad lines in the area of $1350 \mathrm{~cm}^{-1}$ and $1580 \mathrm{~cm}^{-1}$ corresponding to amorphous graphite on a strong fluorescent base. The value of the lines ratio in the $\mathrm{D}$ band $\left(1350 \mathrm{~cm}^{-1}\right)$ and the $\mathrm{G}$ band $\left(1580 \mathrm{~cm}^{-1}\right)$ associated with amorphous graphite results in data on the carbon crystallite size of about $10 \mathrm{~nm}$.

Lines in the area of 108,144 and $215 \mathrm{~cm}^{-1}$ and $650 \mathrm{~cm}^{-1}$ are associated with the $\mathrm{Cu}_{2} \mathrm{O}$ presence. The $\mathrm{Cu}_{2} \mathrm{O}$ percentage decreases sharply as the substrate approaches to the steam flow center, and at the center of the steam flow it is virtually zero (Figure 3).

\subsection{Electron-Microscopy Research Results}

SEM study results of the elemental composition and structure of the coating and its fine structure study in TEM, Figure 3, agree well with the X-ray diffraction and atomic force microscopy results.

Given the relatively small carbon content up to 14 at\%, Figure 3(a), the coating surface is smooth, while on a fracture in the cross-section, a typical columnar structure appears, typical for pure metals.

With increasing carbon content up to 17 at\% and more, Figure 3(b) and Figure 3(c), the coating surface becomes more developed, and the structure on the fracture changes from columnar to a homogeneous fine-grained and disoriented structure. Form the fracture structure view gives the impression of mellowed material consisting of viscous and brittle components. On the coating surface with an 18 at\% carbon content, there is a layer with a developed surface, consisting of large and small globular aggregates. With increasing carbon content of the structure, the structure in the cross section becomes ultrafine, Figure 3(d) and Figure 3(e), the fracture nature is more fragile, and the surface is smoother. The elemental composition analysis of the coating surface and in the fracture cross-sectional area shows a uniform homogeneous content of elements, which indicates the high homogeneity of the two-component material, both composition and structural (high dispersion of copper and carbon).

The high homogeneity of composition and elements dispersion is proved by the pictures of the coating fine structure made by TEM, Figure 4.

The structure of all coating samples, including pure copper, is characterized as a material with extremely fine grains, smaller than $100 \mathrm{~nm}$. The grain size was determined by the intersecting lines on the micrographs at 20 500 thousand-fold zoom, made in light and dark fields. In order to determine the phase composition and texture electron diffraction patterns were obtained using the selector apertures of different composition.

In pure copper, and a relatively small carbon content of up to 14 at\%, the average grain size ranged from 20 to $100 \mathrm{~nm}$, and the growth pattern was observed, Figure 4(a). With increasing carbon content up to 18 at\% and higher, the average grain size decreases to $40 \mathrm{~nm}$, and growth texture almost disappears. Figure 4(b) on the left shows the general structure view. The grains (gray and black background) and the grain boundaries as a grid of white lines are visible. It is possible to compare the thickness of these boundaries with the grain size. It is about



Figure 2. Raman spectra of samples with carbon-copper sputtering, 18\% of carbon: 1 . Scraping from a copper substrate from a peripheral zone. 2. Sputtering in a cold steam flow periphery at a substrate temperature not exceeding $100^{\circ} \mathrm{C}$. 3. Sputtering in the steam flow periphery at a substrate temperature of $350^{\circ} \mathrm{C}$. 4 . Sputtering in the steam flow center at $350^{\circ} \mathrm{C}$. 




(a)

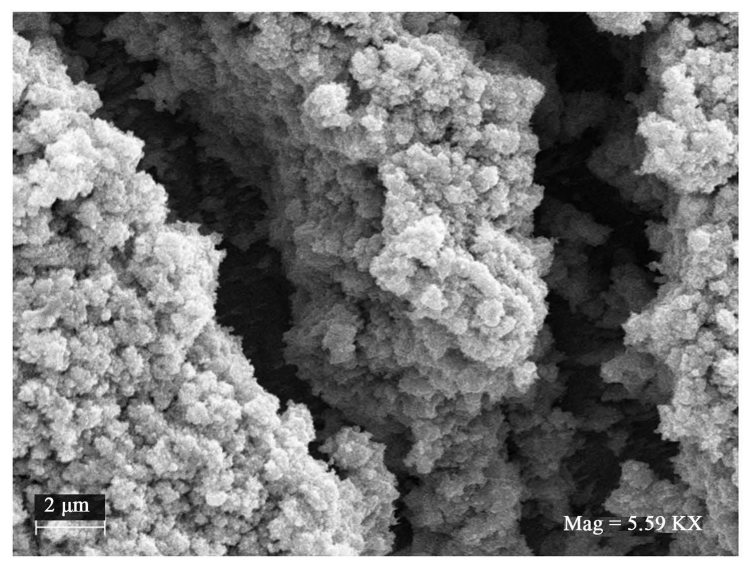

(c)

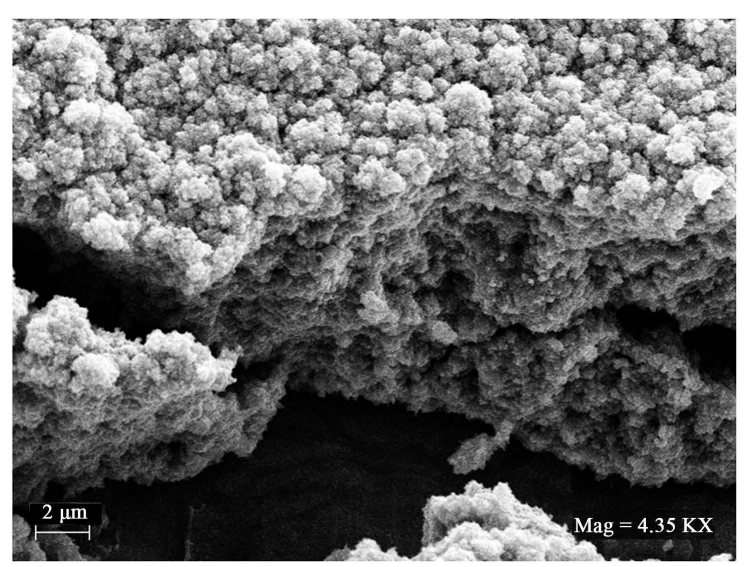

(b)

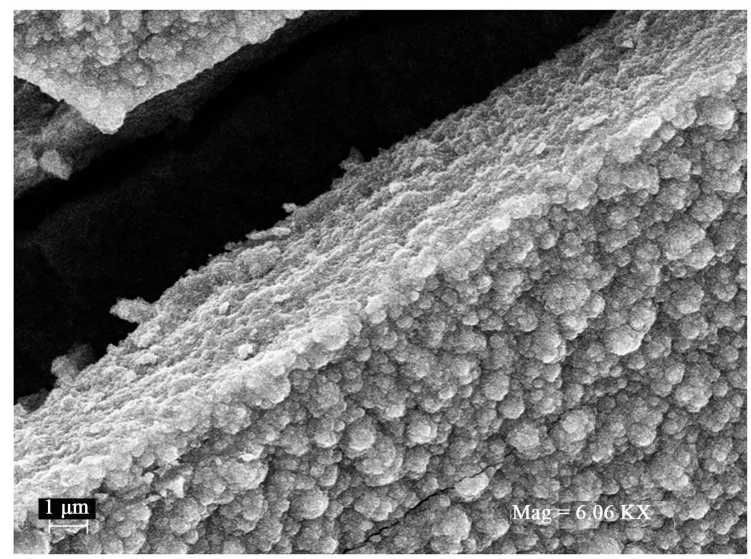

(d)

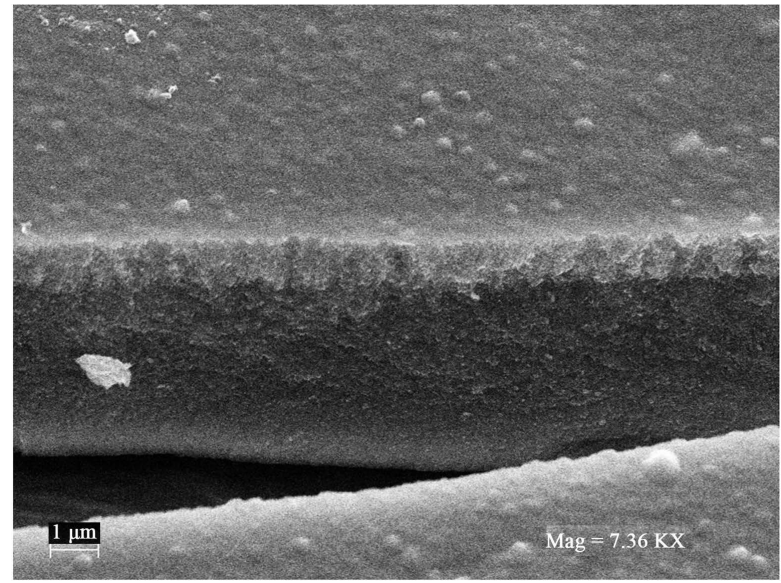

(e)

Figure 3. Copper-carbon coating structure, SEM: (a) 14 at $\%$ C; (b) 17 at $\%$ C; (c) 18 at $\%$ C; (d) 72 at $\%$ C; (e) 86 at $\%$ C.

$0.1-0.15$ of the average grain size. In the structure of the coating with a 72 at\% carbon content, the grain size of copper is reduced to $10-20 \mathrm{~nm}$ and the thickness of the boundaries between the grains remain at the same level and, accordingly, the length of these boundaries increases, Figure 4(a), which can be indirectly associated with an increase in carbon concentration.

At high carbon concentrations, the texture is almost completely missing, and packaging or twins defects fade in micrograins, Figure 4(b) and Figure 4(c), on the left. For a more precise identification of whether these 

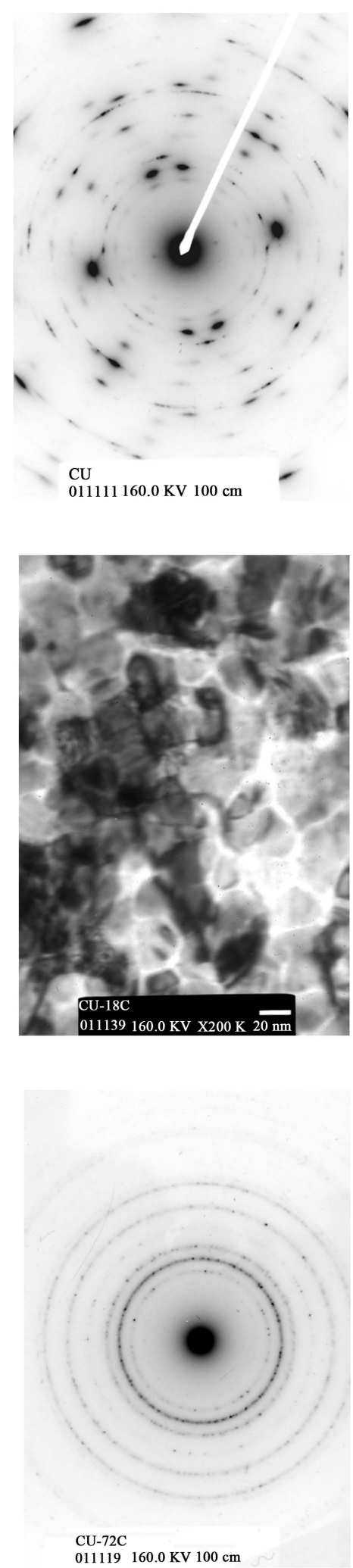
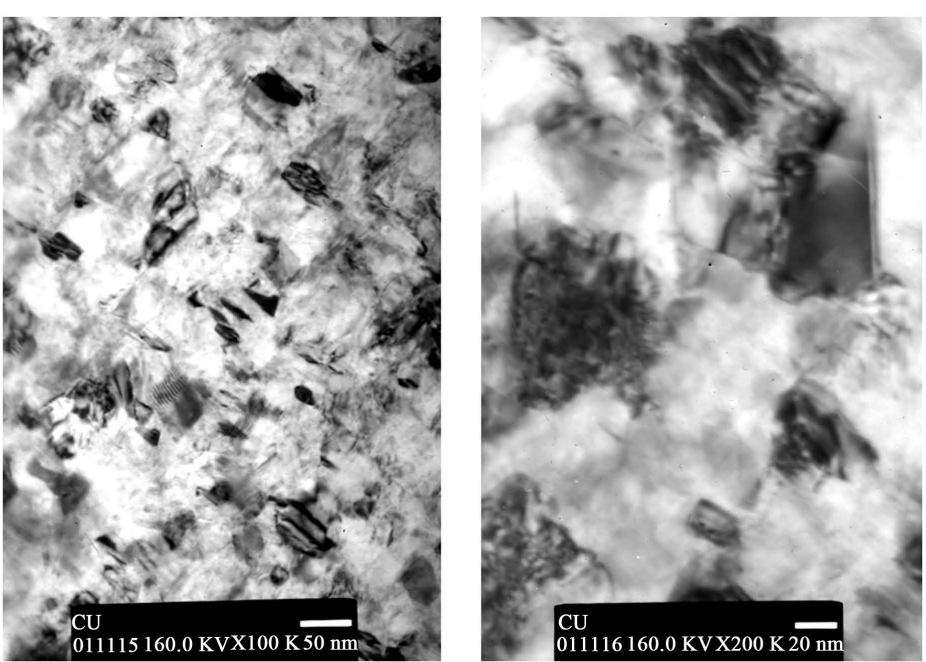

(a)

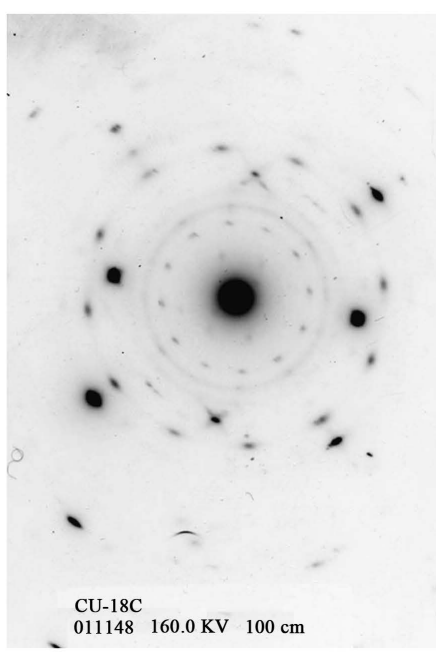

(b)

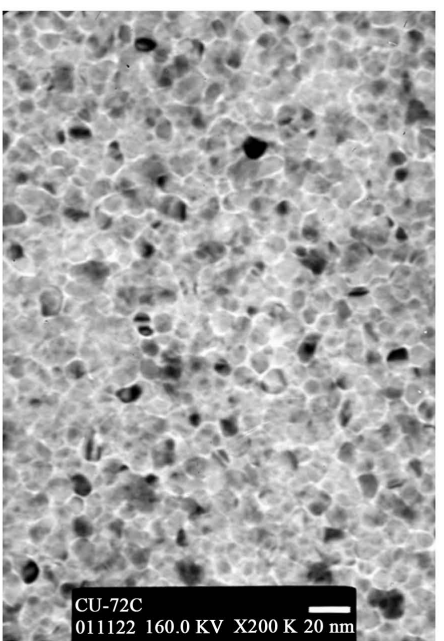

(c)
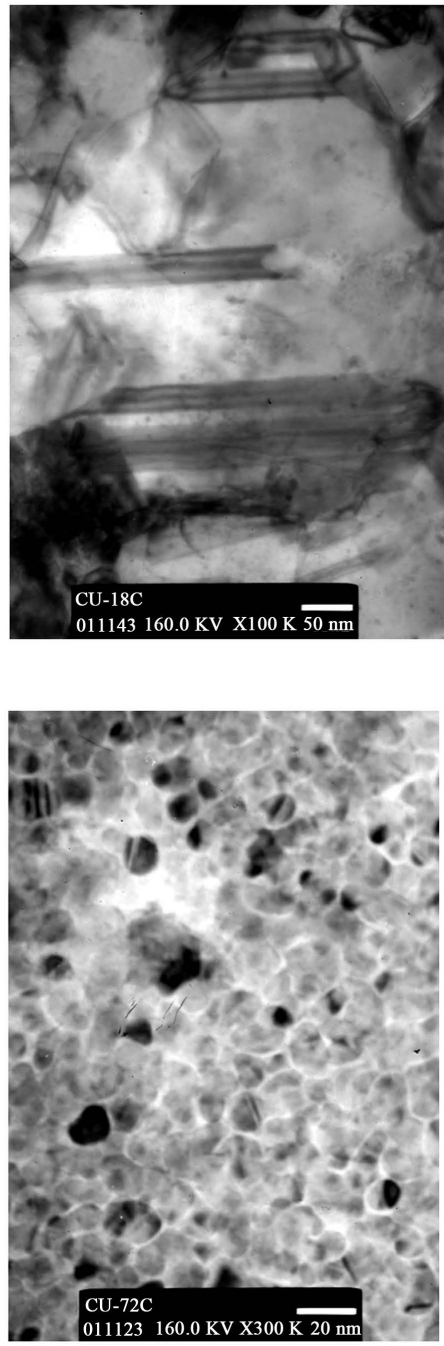

$1143160.0 \mathrm{KV}$ X100 K $50 \mathrm{~nm}$

Figure 4. TEM image of the copper-carbon coating material. (a) pure copper, the structure and electron diffraction pattern; (b) 18 at\% C, the structure and electron diffraction pattern; (c) 2 at\% C, the structure and electron diffraction pattern. 
grains all relate to the copper phase, and the borders - to a carbon, we need an additional structure study in TEM at a resolution less than $1.5 \mathrm{~nm}$, considering the nature of atomic planes arrangement in these areas (grain, boundary).

\subsection{Mechanical and Tribological Properties Research Results}

When applying the copper-carbon composite coatings in the modes from Table 1 , the coating is formed as a compact dense layer, adhesively bound to the surface of substrates both metal and ceramic, and glass as well. Visual inspection of coating adhesion and color on the glass substrates from the inner side shows that the coating adheres evenly across the whole surface. The color of the composite varies from red (for pure copper) with a gradual transition to a pale red with a gray tint with increasing carbon concentration. Monotonic change in the composite color shows a high uniformity of the coating material. The coating color becomes virtually iron-gray when the carbon content is 93 at\%. On the outside, the coating color changes more dramatically-from bright red (pure copper) to dark brown (with 17 at\% carbon) and at 18 at\% carbon, the coating color is velvety black; with increasing carbon content the velvety gradually disappears, and the coating with the carbon content of 72 at\% and above becomes dark gray with a gloss. These color changes, as AFM coating research has shown, is associated not only with the carbon content in the material, but also the nature of the topography and its roughness.

Mechanical effect on such a surface at rolling by a ball with a load of up to $50 \mathrm{~N}$, shows how the protruding crystallite tops are deformed in the first place (Figure 5(a) and Figure 5(b)). The deformation character indicates a high ductility of the composite.

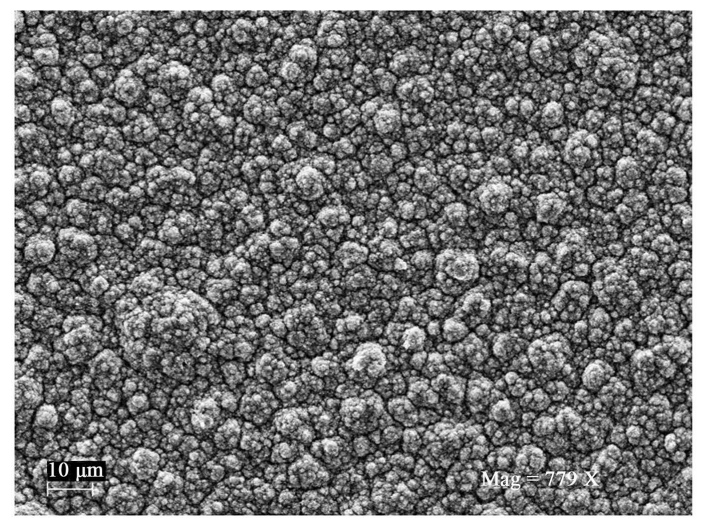

(a)

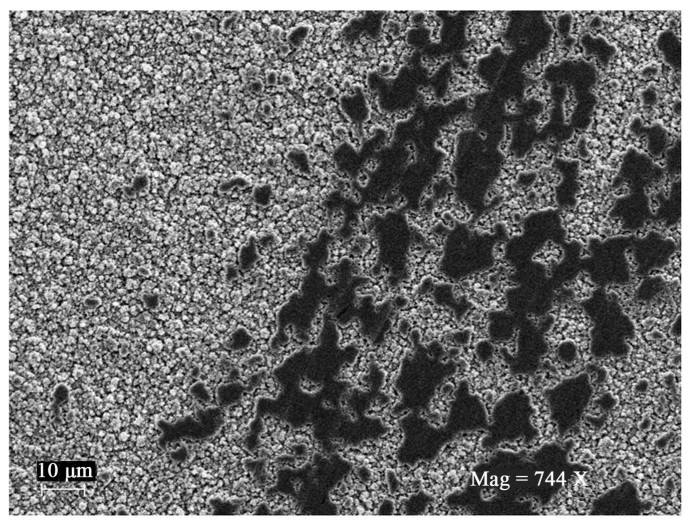

(b)

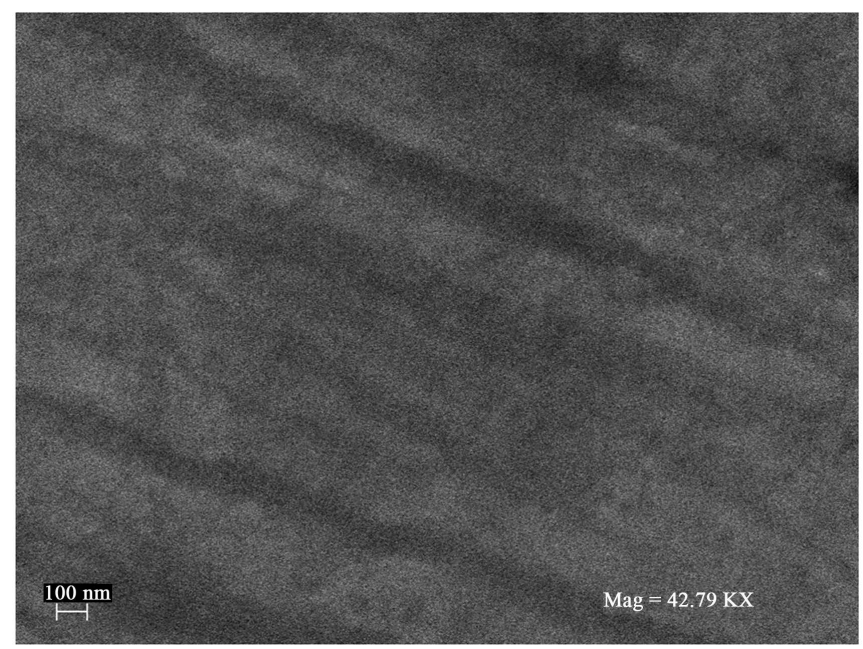

(c)

Figure 5. The surface structure of copper-carbon composite coatings in different types of mechanical impact: (a) the original surface condition; (b), (c) rolling-off by a steel ball under a load of $70 \mathrm{~N}$ : (b) the initial stage; (c) the final stage running. 
During deformation, both in the initial stage, and for a long time, Figure 5(b) and Figure 5(c), the coating does not form cracks and peeling products like flakes of material that indicates a high composite plasticity and a high internal cohesion. X-ray microspectral analysis of the surface layer composition subjected to deformation, shows that at the initial stage, the ratio of copper and carbon does not change. But then, with deeper indentation, the material surface layer is enriched with carbon. For example, in a composite with 18 at\% C, the carbon content increases to 23 - 27 at\%.

At a point indentation of the material with a diamond indenter ( $50 \mathrm{~N}$ load), the composite plastic deformation occurs, but without sticking and without pilling-up typical for the plastic materials. Figure 6 shows the nature of prints from a diamond indenter in the composite coating compared to a pure copper coating, Figure 6(a).

Microhardness measurements show (Table 3) that the carbon content from 14 at $\%$ to 35 at\% (6.0 wt\%), the composite coating material remains plastic and is not inferior to pure copper. With such a high plasticity, the plastic flow of composite material and its high inertness to adhere to the counterface material are due to the presence of carbon and its structure in the composite. These factors combine to determine the mechanical (Table 3), electrical (Table 4), and possibly other properties that are still to be explored. The friction and wear studies of the composite material are presented in Table 3.

Table 3 clearly shows that the composite coatings of copper-carbon with a carbon content in the range from 18 at\% to 35 at\% account for a complex of high plastic properties, durability and adhesion. Coatings with lower carbon content will be closer to the properties of copper, and with a large one-to the properties of pure graphite. Studies of the tribological characteristics (friction and wear coefficient) have shown (Table 3 and Figure 7) that a composite coating has a low dry friction coefficient of $\sim 0.1$ and a high wear resistance $<10^{-17} \mathrm{~m}^{3} / \mathrm{N} \cdot \mathrm{m}$.

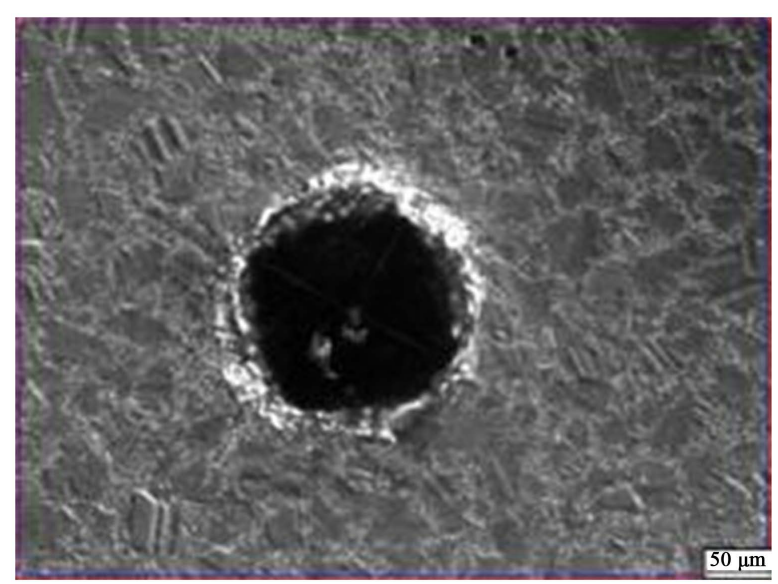

(a)

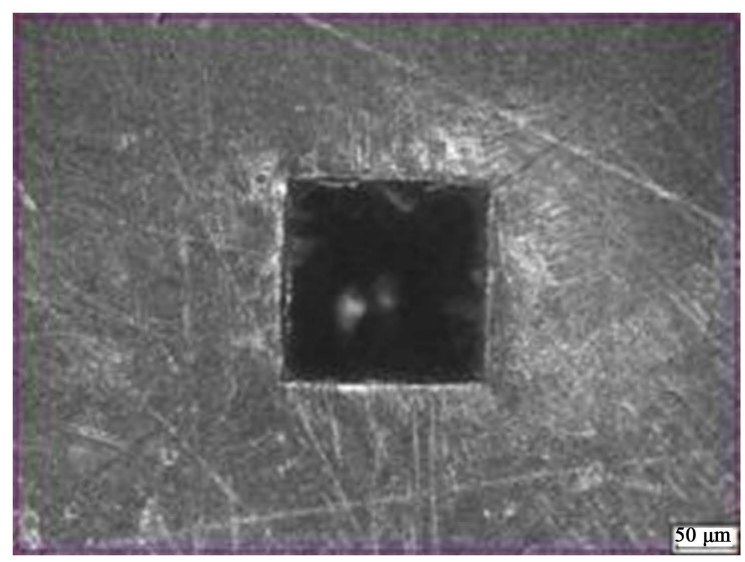

(b)

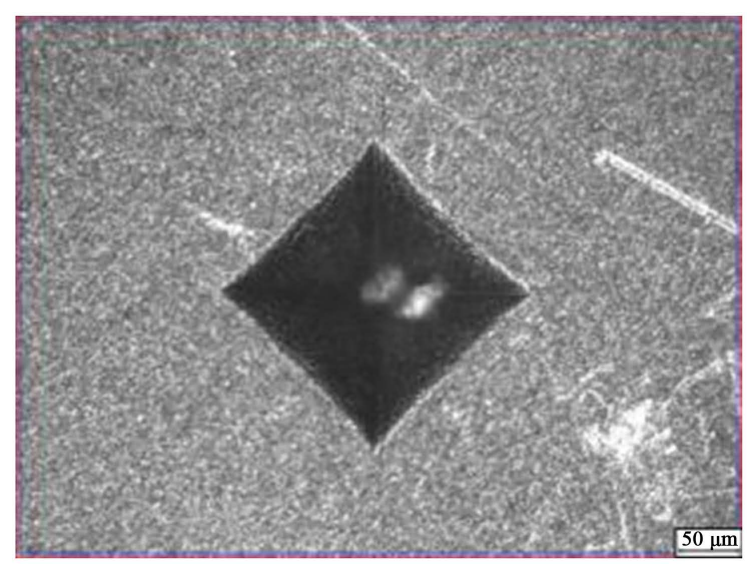

(c)

Figure 6. The surface structure of copper-carbon composite coating at mechanical impact by a diamond indenter at a $50 \mathrm{~N}$ load: (a) pure copper; (b) 14 at $\%$ C; (c) 18 at $\%$ C. 


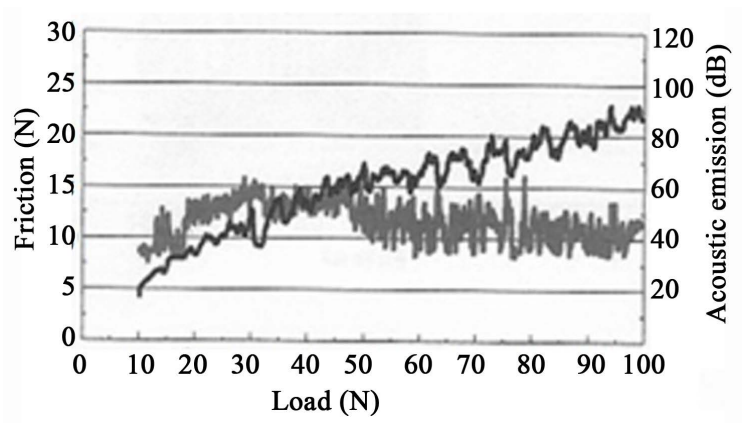

(a)

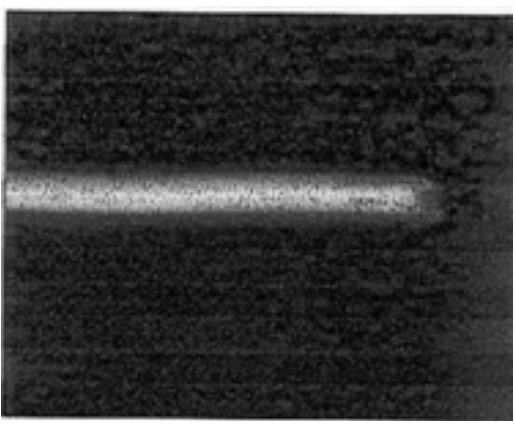

(b)

Figure 7. (a) Characteristic coefficient of friction (along the $y$ axis-coefficient of friction, along $x$ - the load on the indenter in N); (b) type of track left by the indenter at maximum load of $100 \mathrm{~N}$.

Table 3. Mechanical and tribological properties of the copper-carbon composite material.

\begin{tabular}{|c|c|c|c|c|c|c|c|}
\hline \multirow{3}{*}{ № } & \multirow{3}{*}{$\begin{array}{c}\text { Carbon content } \\
\text { in the coating, at } \%\end{array}$} & \multirow{2}{*}{\multicolumn{2}{|c|}{$\begin{array}{l}\text { Coating microhardness } \mathrm{H}_{\mathrm{V}} \text {, } \\
\mathrm{kg} / \mathrm{mm}^{2} \text { load } 0.1 \mathrm{~N}\end{array}$}} & \multirow{3}{*}{$\begin{array}{c}\text { Friction coefficient } \mu \\
\text { PiN-on-DISC, BK-8 indenter } \\
\text { Load }>100 \mathrm{~N}\end{array}$} & \multirow{3}{*}{$\begin{array}{c}\text { Wear } \\
\text { resistance, } \\
\mathrm{m}^{3} / \mathrm{N} \cdot \mathrm{m}\end{array}$} & \multicolumn{2}{|c|}{ Adhesion } \\
\hline & & & & & & Scratch & Puncture, 5 kg \\
\hline & & Initial & After annealing & & & $\mathrm{N}$ & $-1+$ \\
\hline 1 & Pure copper & 127 & 123 & 0.36 & $<10^{-15}$ & $>50$ & + \\
\hline 2 & 18 & 184 & 191 & 0.15 & $<10^{-17}$ & $>60$ & + \\
\hline 3 & 28 & 200 & 195 & 0.10 & $<10^{-17}$ & $>60$ & + \\
\hline 4 & 35 & 210 & - & 0.06 & $<10^{-17}$ & $>60$ & + \\
\hline 5 & 72 & 230 & - & 0.25 & $<10^{-16}$ & 40 & $-1+$ \\
\hline 6 & 86 & 200 & - & 0.20 & $<10^{-15}$ & 30 & - \\
\hline 7 & 93 & 300 & - & 0.15 & $<10^{-13}$ & 15 & - \\
\hline 8 & 100 & - & - & 0.10 & $<10^{-13}$ & 10 & - \\
\hline
\end{tabular}

Table 4. Specific electrical resistivity of the copper-carbon composite material.

\begin{tabular}{|c|c|c|c|c|c|}
\hline \multirow{2}{*}{ № } & \multicolumn{2}{|c|}{ Content in the composite, at. \% } & \multirow{2}{*}{$\begin{array}{c}\text { Coating } \\
\text { thickness, } \\
\mu \mathrm{m}\end{array}$} & \multirow{2}{*}{$\begin{array}{l}\text { Resistivity, } \\
\mu \mathrm{Ohm} \cdot \mathrm{cm}\end{array}$} & \multirow{2}{*}{ Notes } \\
\hline & $\mathrm{Cu}$ & $\mathrm{C}$ & & & \\
\hline 1 & 100 & - & 45 & 2.0 & tabulated value $1.78 \mu \mathrm{Ohm} \cdot \mathrm{cm}$ \\
\hline 2 & 82 & 18 & 36 & 22.5 & - \\
\hline 3 & 65 & 35 & 16 & 131.0 & - \\
\hline 4 & 28 & 72 & 4.0 & 650.0 & - \\
\hline 5 & 14 & 86 & 4.8 & 1360.0 & - \\
\hline 6 & 7 & 93 & 3.6 & 8100.0 & - \\
\hline 7 & - & 100 & 1.5 & 2200.0 & tabulated value $\mu \mathrm{Ohm} \cdot \mathrm{cm}$ \\
\hline
\end{tabular}

\subsection{Electrical Properties}

Specific electrical resistivity of the composite, Table 4, becomes sharply closer to the graphite electrical resistivity value at the carbon concentration above 35 at\%. When the carbon concentration is 72 at $\%$ and 86 at $\%$, the resistivity grows by 5 times in the first case, compared with 35at\%, while in the second case, is of scale greater than the tabulated value of the graphite electrical resistivity.

An electrical resistivity value for the composite with a 93 at\% carbon content should be considered separately. It exceeds the MPG-7 graphite resistivity by almost 8 times, and for the coating of pure graphite, made in this setup, 2-fold. Why is this resistivity growth anomaly? Apparently, firstly, the dispersed structure has a strong influence in both cases, and also we observe an effect of introducing small quantities of donor material to a ma- 
terial with pronounced acceptor properties. In this regard, there is an absorption of some copper conduction electrons and a partial neutralization of the carbon conduction electrons. This explains, apparently, a sharp jump in electrical resistivity after $>35$ at\% introduction of carbon.

\section{Conclusions}

Composite coatings were prepared firstly by using the HiPS method with direct spraying of copper and graphite without the use of reactive gases like methane, acetylene etc. The carbon concentration in the coating was varied from 14 at\% to 93 at\%. The sputtering process is carried out at high-speed mode with a discharge power density > $40 \mathrm{~W} / \mathrm{cm}^{2}$.

- As a result of such deposition conditions, the composite material layers with a thickness from 3.6 to $36 \mu \mathrm{m}$ were obtained. In other works [8] [9] the composite material layer thickness did not exceed $560 \mathrm{~nm}$. The coatings obtained in this study belong already to a class of nanostructured coatings that can be used in mechanical engineering to modify the working surface with a roughness $R_{\mathrm{a}}$ from 0.5 to $3.5 \mu \mathrm{m}$ (grinding, chiselling).

- Despite the unusual nature of the composite components, that do not interact with each other metallurgically and that cannot be efficiently mixed at an atomicor at least an ultradisperse level of conventional metallurgy techniques, the coatings obtained from this composite are in a compact state and have a high adhesion to substrates of different materials.

- At mechanical stress on the composite material, it does not disintegrate into separate fragments, and behaves like a metal with mechanical, plastic and frictional properties significantly higher than those of its components-copperand carbon. The composite coating has a low dry friction coefficient of $\sim 0.1$ and a high wear resistance $<10^{-17} \mathrm{~m}^{3} / \mathrm{N} \cdot \mathrm{m}$

- At copper concentrations of about $7 \%$, the composite represents a material with an anomalously high resistivity $\rho \approx 8.1 \times 10^{3} \mu \mathrm{Ohm} \cdot \mathrm{cm}$, which is significantly higher than that of pure graphite $\left(1.3 \times 10^{3} \mu \mathrm{Ohm} \cdot \mathrm{cm}\right)$.

The nature of these and other anomalous properties of the composites is related, primarily to the composite structure, its phase and chemical composition, as well as the interaction features of the charged structural elements based on copper and carbon (Figure 1). Full identifying these structural elements in this study, as well as the bonding mechanism of the copper crystallites and the carbon structures is a task of further investigation. A more detailed study of the composite plastic properties and the influence of copper on the carbon electrical resistance is of great interest. The research on these properties is important for further technological applications of structural coatings in mechanical and electrical engineering.

\section{Fund}

This study was supported by the Russian Foundation of Basic Researches (projects: № 16-07-00469; № 1407-00277).

\section{References}

[1] Astashinskaya, M.V., Dub, S.N. and Khodasevich, V.V. (2013) The Microstructure and the Nano-Hardness of Copper-Carbon Coatings Formed by Plasma-Enhanced Chemical Vapor Deposition. 10th International Conference "Interaction of Radiation with Solids”, 24-27 September 2013, Minsk.

[2] Korolyanchuk, D.G., Nefedov, V.G., Bukatina, M.R., Schebelskaya, M.P., Zakharov, V.D. and Vaganov, V.E. (2014) Electrolytic Composite Coatings Based on Copper with Carbon Nanomaterials. Bulletin of the National Technology University "Kharkov Polytechnical Institute”. No. 30, 1139.

[3] Piliptsov, D.G., Rogachev, A.V., Fedosenko, N.N. and Bekarevich. R.V. (2010) Mechanical Properties of the Copper Alloyed Carbon Coatings Deposited from Cathodic Pulse Plasma. Problems of Physics, Mathematics and Technology, (Belarus), No. 3, 25-30.

[4] Pauleau, Y. and Thiery, F. (2002) Nanostructured Copper-Carbon Composite Thin Films Produced by Sputter Deposition/Microwave Plasma-Enhanced Chemical Vapor Deposition Dual Process. Materials Letters, 56, 1053-1058.

[5] Shiryaev., S.A., Atamanov, M.V., Guseva, M.I., Martynenko, Y.V., Mitin, A.V., Mitin, V.S. and Moskovkin, P.G. (2002) Production and Properties of Metal-Carbon Based Composite Coatings with a Nanocrystalline Structure. Technical Physics, 72, 99-104.

[6] Mitin, V., Sharipov, E. and Mitin, A. (2006) High Deposition Rate Magnetrons-Innovative Coating Technology: Key 
Elements and Advantages. Surface Engineering, 22, 1-6.

[7] Teer Coatings Ltd Data Sheet (2006) Thin Film Coating Test Equipment. Tester Ball-Crater the BC-1. www.teercoatings.co.uk

[8] Uglov, V.V., Anishchik, V.M., Kuleshov, A.K., et al. (2003) Relationship of Microstructural State and Mechanical Properties of Carbon and Metal-Carbon Coatings Formed Byplasma-Enhanced Chemical Vacuumed Position. Advanced Materials, №. 6, 5-11.

[9] Polo, I., Thiery, F., Pelletier, J., Uglov, V., et al. (2002) Structure and Mechanical Properties of Nano-Structured Metal-Carbon Coatings Formed by Plasma-Chemical and Vacuum Arc Deposition. Advanced Materials, № 5, 13-19. 